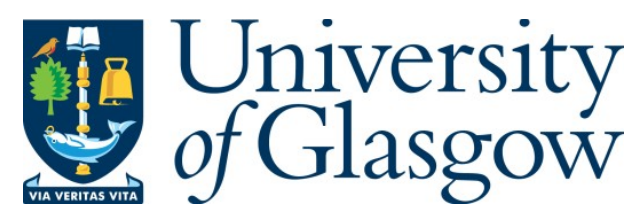

Spanò, R., Tomo, A. and Parker, L. D. (2021) Shifting identities in the public sector: portraying the "new" public manager in the Italian setting. Qualitative Research in Accounting and Management. (Early Online Publication)

(doi: 10.1108/QRAM-02-2021-0032)

This is the Author Accepted Manuscript.

There may be differences between this version and the published version. You are advised to consult the publisher's version if you wish to cite from it.

http://eprints.gla.ac.uk/257498/

Deposited on: 21 October 2021

Enlighten - Research publications by members of the University of Glasgow http://eprints.gla.ac.uk 
Shifting identities in the public sector:

Portraying the 'new' public manager in the Italian setting

\section{Rosanna Spanò}

Assistant Professor of Accounting

Department of Economics, Management, Institutions

University of Naples "Federico II"

Complesso Universitario Monte S. Angelo

Via Cinthia 26 - 80126 - Naples, Italy

+39081675291

rosanna.spano@unina.it

\section{Andrea Tomo}

Assistant Professor of Organization Studies

Department of Economics, Management, Institutions

University of Naples "Federico II"

Complesso Universitario Monte S. Angelo

Via Cinthia 26 - 80126 - Naples, Italy

+39081675289

andrea.tomo@unina.it

\section{Lee D. Parker}

RMIT Distinguished Professor

School of Accounting RMIT University

Melbourne, Victoria, Australia

$+61(0) 428248309$

lee.parker@rmit.edu.au

Research Professor of Accounting

University of Glasgow

Scotland, UK

Lee.Parker.2@glasgow.ac.uk 


\title{
Shifting identities in the public sector: \\ Portraying the 'new' public manager in the Italian setting
}

\begin{abstract}
Purpose This paper aims to understand how training programs fostering discourses centred on individuals' identity construction may turn resistance into a generative and enabling force to elicit more relationally and negotiated solutions of change.

Design The study used Foucault's conceptualisation of 'regimes of truth' to show how even potentially resistant public managers may generatively contribute to change processes if given the chance to restate the macro discourses of the hegemonic New Public Management movement at their own micro level. It relied upon an ethnographic approach based on verbal interviews, photoelicitation, DiSC behavioural tests, and observation of 29 Italian public managers participating in a training course.
\end{abstract}

Findings The findings allow us to unveil how helping public managers to think about their selfidentity in new ways enabled them to approach changing processes differently turning their resistance efforts into a generative force.

Value The paper offers a noteworthy contribution to the literature on public sector change by examining neglected issues relating to the identity of change agents and the implications of their multiple roles. It presents an alternative to the deterministic view of resistance as impeding or dysfunctionally shaping change under the New Public Management approach. This has important implications for both practice and policymaking.

\section{Keywords}

Identity, New Public Management, Regimes of Truth, Resistance, Public Sector, Italy

\section{Introduction}

Accounting and management change research to date has largely focused on the societal and organisational levels, disregarding the role of the individual (Brown, 2019). Organisation-centric studies have not paid detailed attention to dimensions such as individuals' perceptions of change, emotions, and identity issues (Goretzki et al., 2013; Hay et al., 2020). This paper therefore draws on recent literature (Broadbent and Laughlin, 2013; Fiondella et al., 2016; Spanò et al., 2020) to acknowledge the importance of individuals as change agents. It highlights the relevance of understanding how individuals can actively shape organisational development trajectories through the introduction of accounting measures and techniques (see Carlsson et al., 2016). It explores how they understand, interpret, and convey changes (Blomgren, 2003; Kärreman and Alvesson, 2004; Sveningsson and Alvesson, 2003; Watson, 2008, 2009), which may involve adapting and transforming their own identities.

This is relevant in the public sector, where New Public Management (NPM) was initially conceived as an identity project based on new professional and managerial subjectivities (Du Gay, 1996; Meyer 
and Hammerschmid, 2006; Thomas and Davies, 2005; Meyer et al., 2014). However, it soon became deterministic, a hegemonic regime (Laclau and Mouffe, 1985) that placed a heavy focus on performance measurement, efficiency and (coercive) accounting tools, overlooking the relational and identity issues that lie at the heart of organisations. These circumstances led to individuals reacting to top-down imposed logics through formal ('tick-box') compliance or direct rebuttal, therefore impeding or eliminating change (Thomas and Davies, 2005; Broadbent and Laughlin, 1998; Broadbent et al., 2001; Broadbent and Laughlin, 2013; Robbins, 2007).

This paper explores NPM change from a broader perspective. It goes beyond the more commonly explored themes, dealing with "what" questions surrounding change, and taps into "how" these processes takes place (Jacobs, 2005; Liguori and Steccolini, 2014). In doing so, it focuses in particular on the dynamics of identity construction of those involved, and how these shape change. This approach follows Allain et al. (2021), who showed how public managers experiencing professional dehumanisation from reforms were able to subtly and creatively resist change. They did so by mobilising new public management accounting tools, sometimes ending up at the opposite point from the original desired outcome. This strengthened the neoliberal nature of the reform they wanted to contrast. Differently from Allain et al. (2021), the current study takes an even broader stance, aiming to understand how identities be acted upon in the backstage of NPM change processes, influencing the course of change. Here, the aim is not necessarily to avoid resistance, but to turn this force into a potential enabler for greater acceptance. This view of resistance comes from Thomas and Davies (2005), who reflected Foucault's conceptualisations to develop a view of 'generative resistance', making clear that there could be more nuanced and fluid expressions of power and agency. They illustrated the process of the micro-politics of resistance deriving from the identity struggles of public managers, but they did not provide any understanding of how individuals enact different behaviours. Thus, bearing in mind that discursive forces can play a major role in becoming processes (Sveningsson and Alvesson, 2003) for the purposes of the study we used Foucault's conceptualisation of 'regimes of truth'. The aim is to understand how a change in the discourses, and in the regimes of truth determined by these discourses, may lead to different responses. It allows to understand how it is possible to switching from rebuttal attitudes towards more generative kinds of resistance. This study therefore overcomes the polarisation of the accounting change debate (Spanò et al., 2020) bringing together theories of resistance vs success and hybridisation (e.g., Broadbent et al., 2001; Gurd and Thorne, 2003; Abernethy and Vagnoni, 2004; Jacobs et al., 2004; Kurunmaki et al., 2003; Kurunmaki, 2004; Kurunmaki and Miller, 2006; Mir and Rahaman, 2006).

Given the focus on the processes of identity construction, the themes under scrutiny are investigated looking at training initiatives, important yet overlooked issues. Indeed, there is a tendency within the NPM agenda to rely upon training initiatives to achieve the desired aims. Habitually, training initiatives have been used to select and professionalise public sector employees, and to make them feel part of "high potential programs" or "communities of practice" (Meyer and Hammerschmid, 2006; van Bockel and Noordegraaf, 2006). This approach was designed to limit resistance to change. However, these training initiatives can frequently lead to contradictions and over-simplified solutions. These may in turn endanger individual professional identities, leading to personal conflict, and triggering opposition. This may have important implications for change. However, Becker et al. (2014) noted that these issues are relatively unexplored in the literature, and constitute an important area for future enquiry. This paper therefore aimed to answer the following research question:

How may training programs fostering discourses centred on individuals' identity construction turn resistance into a generative and enabling force to elicit more relationally and negotiated solutions of change? 
We focused on the Italian public sector, where radical NPM changes have resulted in intense regulatory activity designed to deliver financial accountability, the development of a range of measures of efficiency to assess individuals, units and organisations, marketisation between service providers and within organisations; and a changing relationship between providers and citizens (Hood et al., 2000). In Italy, the original intention was to promote individual professionalisation and managerialism. However, the increasing pressure to achieve short-term efficiency (even at the risk of compromising quality), and to measure everything, has led to greater standardisation of practices and procedures (Spanò, 2018; Tomo, 2018). The implementation of these changes has often produced poorly motivated public managers who passively accept initiatives in a process of ceremonial adoption. However, this process gives limited or no long-lasting substantive effects on public sector practices and performance.

Following Warren and Parker (2009) and Parker and Warren (2017), this study used a theoretically informed ethnographic approach. It was based on a hybrid strategy combining interviews with the use of photo-elicitation and photo-voice, DiSC behavioural tests ${ }^{\mathrm{i}}$, and participant observation. The study took place during a one-year higher training course at the University of Naples Federico II in 2017-2018, attended by 29 public managers. The training program was a publicly funded Executive MBA on managerialism in the public sector. The rationale of the program was to overcome the boundaries and limitations set over the years by the NPM agenda, to regain a deeper focus on identity and behaviours as a way to elicit greater acceptance of change among public managers. It was therefore publicly funded, but conceived as an experiment and not under any pressure from central government to provide particular content or course shape.

The findings show how identity-centred discourses affect potentially resistant public managers. These managers, struggling with their unwanted selves, may turn resistance into a generative force rather than a violent rebuttal of more relationally and negotiated solutions. The analysis demonstrates how even potentially resistant public managers may generatively contribute to change processes when they are given the chance to re-work the macro discourses of the hegemonic NPM movement at their own micro level. This approach allowed us to uncover processes in which public sector managers do not fully subjugate themselves to NPM agendas but also do not fully resist those agendas.

The remainder of this paper is organised as follows. The second section assesses previous literature. The third section presents the theoretical framework. The fourth section explains the research design. The fifth section illustrates the findings. The sixth section discusses the results and offers some concluding remarks.

\section{Challenging issues in public sector change and identity}

This section aims to summarise the main challenges and issues in the accounting and management change literature, and how considering identity implications is becoming paramount. It moves from a more general stance, to discuss the details of the public sector, the focus of this study.

Research on accounting and management change has been extensive but there is still an imbalance between organisation-centred and individual-centred studies (Brown, 2019). This imbalance has led organisation-centred researchers to devote attention to what kind of changes take place within the firms. This has often ignored consideration of how changes take place (Jacobs, 2005; Liguori and Steccolini, 2014). In line with this, Spanò et al. (2020) contended that the literature has tended to advance polarised views of resistance $v s$ success or hybridisation (e.g., Broadbent et al., 2001; Gurd and Thorne, 2003; Abernethy and Vagnoni, 2004; Jacobs et al., 2004; Kurunmaki et al., 2003; 
Kurunmaki, 2004; Kurunmaki and Miller, 2006; Mir and Rahaman, 2006). However, the extant debate has paid little attention to how certain phenomena occur and especially to change agents and their roles. In most of the research published, resistance generally derives from clashing cultures, lack of understanding of the rationale for change and its impact, and communication barriers among participants from heterogeneous backgrounds. Studies have found that successful changes and hybridisation emerges when accounting is mobilised to supersede these limitations, becoming a means of mediation between individuals who might otherwise be in conflict (Wickramasinghe, 2015; Mir and Rahaman, 2006; Spanò et al., 2020; Fiondella et al., 2016; Agyemang and Broadbent, 2015). There is raising consensus o the need for more inquiry into the range of changes between these two extremes (Broadbent and Laughlin, 2013; Fiondella et al., 2106; Spanò et al., 2020), by understanding change agents and their roles in shaping how changes take place within organisations.

Broadbent and Laughlin (2013) highlighted the importance of change agents in fostering accounting changes that are deemed to be acceptable to those involved, including a much more nuanced idea of change outcomes beyond resistance vs success or hybridisation. In the 1990s, Jönsson and Solli (1993) explored a caring setting, and emphasised that 'accounting talk' may give individuals the chance to articulate projects to be developed within organisations, rather than passively accepting impositions. This is a crucial generator for future improvements. They emphasised the importance of organisational learning and training, paving the way for closer consideration of identity construction issues. Likewise, Carlsson et al. (2016) discussed the importance of initiatives designed to support organisational members' general understanding of financial issues and forge specific links between accounting concepts and work practices, to support effective changes. Spanò et al. (2020) showed how individual engagement and understanding of forthcoming changes to accounting culture fostered more proactive support of organisational change.

These studies are unanimous in highlighting that the individual dimension has often been overlooked. They support the increasing awareness that exploring individual perceptions, behaviours, emotions and identity transformation/adaptation dynamics is essential for the current and future research agenda (Goretzki et al., 2013; Hay et al., 2020). These dimensions of analysis are vital to appreciate how change agents (Broadbent and Laughlin, 2013; Fiondella et al., 2016; Spanò et al., 2020) understand, interpret, and convey changes (Blomgren, 2003; Kärreman and Alvesson, 2004; Sveningsson and Alvesson, 2003; Watson, 2008, 2009).

Identity studies is a broad field (Alvesson et al., 2008; Corlett et al., 2017) with multiple streams of inquiry that often interconnect and sometimes overlap (Brown, 2019). There are studies focusing on identity conceptualisation (Brown, 2006; Slay and Smith, 2011; Zanoni et al., 2017), and how identities shape organisational outcomes (Brown and Toyoki, 2013; Wright et al., 2012). There are also papers on the politics of corporate (Rodrigues and Child, 2008) and professional identity construction (Goretzki et al., 2013; Tomo and Spanò, 2020). Other studies consider dis-identification and self-alienation (Costas and Fleming, 2009), or the relationship between a personal identity that is relatively stable over time, and a work identity that is more fluid and affected by groups and contacts (Empson, 2013). Finally, there are studies of the micro-politics of identity construction (Brown, 2015; Allain et al., 2021) and how they may have meso- and macro-level consequences.

For our purposes, it is worth clarifying that considering identity dynamics is essential to understand how change processes take place in the public sector, where the NPM initially conceived as an identity project failed to achieve this expectation (Meyer et al., 2014). Instead, NPM developed as a hegemonic regime (Laclau and Mouffe, 1985) with a heavy focus on performance measurement, efficiency and (coercive) accounting tools, and overlooking the relational and identity issues that lie at the heart of organisations. This suggests that public managers may adopt different identities depending on the values and beliefs associated with their perceptions of the role of public servants, 
their objectives and the criteria driving performance measurement (Meyer and Hammerschmid, 2006; Rautiainen and Jarvenpaa, 2012). This is a consequence of the NPM tendency to replicate private sector logic (Hoque et al., 2004; Meyer and Hammerschmid, 2006; Skålen, 2004). This imported logic is often accompanied by the introduction of new vocabularies, categorisations and ideals, which individuals draw upon when communicating, constructing, and understanding their identities (Bankins and Waterhouse, 2019; Meyer and Hammerschmid, 2006). Palma et al. (2010) argued that NPM reforms risk, removing what is distinctive about public organisations without providing adequate meaning and stability to employees. This therefore creates heterogeneous, conflicting and fluid organisational identities, rather than consistent and stable ones (Bankins and Waterhouse, 2019; Skålen, 2004). Van Bockel and Noordegraaf (2006) noted that uncertainty and confusion arise because of inconsistency between stakeholders' perception of an appropriate entrepreneurial approach for the public service, and the traditional assumption that public sector employees should follow public service ideals. The literature stresses that imposed logic and practices might create an identity cage clashing with personal actual and desired identities, leading to uncertainty. Allain et al. (2021) interestingly addressed the inner conflicts of public managers dealing with externally imposed changes that were perceived as de-humanising. They noted that managers' intolerance of the new approach triggered subtle and creative resistance strategies, which were delivered through the accounting tools introduced under NPM initiatives. Interestingly, in some cases, this opposition actually strengthened the neoliberal dynamic of the reform the individuals wished to oppose.

There is, however, little research on how identities can be acted upon in the backstage of NPM changing processes. It is still unclear how they can influence the course of change by not necessarily avoiding resistance but turning this force into a potential enabler for greater acceptance. However, this is arguably fundamental in overcoming the polarisation of the accounting debate on resistance $v s$ success or hybridisation.

To examine this issue, it is worth referring to Thomas and Davies (2005). They drew empirical evidence from multiple settings in the UK, including the police, social services and secondary education, to provide examples of the micro-politics of resistance. They suggested that these actions may extend beyond a reaction to repressive power and have the potential to facilitate positive outcomes for the organisation. They argued that neglect of public managers' identity questions, and top-down imposition of logics, practices and discourses, induce compliance or rebuttal. This consolidates an idea of resistance as impeding or dysfunctionally shaping NPM change. Thomas and Davies (2005) noted that resistance under the NPM has been wrongly seen only as a violent reaction to repressive power and coercive approaches. Instead, they argued that resistance is not restricted to rebuttal or ceremonial adoption of new procedures but is much more multifaceted (a view which was shared by Kärreman and Alvesson, 2009). Thomas and Davies (2005) suggested re-focusing on issues of meaning and subjectivity, and looking at resistance by considering multidirectional and generative effects in identity construction. They emphasised challenges as well as reinscription and reproduction of the discourses of change, in considering generative resistance. Drawing on Thomas and Davies' (2005) conception of generative resistance, we used Foucault's conceptualisation of 'regimes of truth' as a theoretical lens. This framework, which is explored further in the next section, allowed us to understand how a change in the discourses, and in the regimes of truth determined by these discourses, may lead to different responses. It allows to understand how it is possible to switching from rebuttal attitudes towards more generative kinds of resistance.

To tap into these issues, the paper cannot resile from the fact that the NPM agenda has long relied upon training initiatives to select and professionalise public sector employees with university degrees, including MBA (Master's in Business Administration) and MPA (Master's in Public Administration) awards. These initiatives were based on discourses designed to align individuals' interests with those of the public sector as a whole and make them feel part of "high potential programs" or "communities 
of practice" (Meyer and Hammerschmid, 2006; van Bockel and Noordegraaf, 2006). This, in turn, was designed to limit resistance to change. Prevailing discourses aimed to promote ideas of individual professionalisation and managerialism, rather than the practice of short-term efficiency, measurement and standardisation (van Bockel and Noordegraaf, 2006). However, many public sector initiatives were often affected by internal contradictions, leading to the adoption of quick and simple practical solutions (e.g., performance-related pay), used in either superficial or vacuous ways, and not automatically carrying appropriate identities and behavioural guidelines (van Bockel and Noordegraaf, 2006). They also involved the introduction of, and excessive reliance upon, accounting and other business measurement tools. This resulted in the (apparent) identity of a "super" manager who has everything under control. However, it did not consider the impact on individual identities, relationships and behaviours. The new business-like identity may conflict with principles of public interest, leading to internal conflict and resistance from public officials. Instead, when training initiatives use appropriate discourses about recovering individual identities, there is the chance that resistance may become a enabling force enabling the change process (see for instance Goretzki et al, 2013). With this in mind, this paper aimed to understand how training programs fostering discourses centred on individuals' identity construction may turn resistance into a generative and enabling force to elicit more relationally and negotiated solutions of change.

\section{Foucault's regimes of truth}

This study drew on the Foucauldian approach $(1972 ; 1981)$. Michel Foucault's inaugural lecture at the Collège de France on The Order of Discourse (1981) is fundamental to exploring his theoretical approach, which has developed since the 1970s. In this lecture, Foucault outlined his critical approach to the relationship between discourse, truth and power. He analysed how societal discourse is controlled and selected, to avoid both powers and dangers, and therefore kept under control. Foucault's interests turned from the analysis and exposure of disciplinary or governmental limits to a concern with contemporary conditions and possibilities for freedom. He provided an illuminating framework explaining how power and control induced by a superior entity (i.e., a regime) influence individual behaviours and identities, forcing them to conform to the imposed logics, practices, and discourses.

Foucault's conceptualisation of 'regimes of truth' is particularly suitable for this paper. In line with Glynos and Howarth (2007), we considered NPM as a regime with its own rules, norms, and accepted practices (i.e., social logics). Accepted practices (social logics) can exert influence and power upon organisations and individuals when they become institutionalised, even informally. These practices are also reproduced through discourses and social interaction within the same community. When the regime is contested, its social logics are opposed by political logics (i.e., mobilising processes that accompany the establishment, challenge and defence of those social logics) with the aim of establishing new practices, rules and norms. This process of contestation can potentially subvert the existing regime, leading to a new one based on different social logics. This is what happened with NPM: it imposed new rules and practices in place of the previous and more bureaucratic public administration approach. However, in the long run, the new social logics from NPM started to be contested, especially at the individual level. This is because individuals who had just emerged from the bureaucratic "cage of rationality" found themselves stuck in an "identity cage" provided by the accounting tools.

Foucault's views have been largely adopted in identity-focused literature (Brown, 2019). Identity is seen by Poststructuralists as evolving in a non-linear way, and shaped by language (Weedon, 1997). Foucault interpreted discourse as "the general domain of all statements, and sometimes as a regulated 
practice that accounts for a number of statements" (Foucault, 1972, p. 80). Discourses provide conditions that enable people, according to the rules of true and false statements, to be produced, or constituted as "subjects". The way in which discourses intersect, compete and collide produces the subject (Foucault, 1981). We suggest that for this paper, there are several competing discourses involved.

We explored the Italian public sector, because it offers revealing examples of contrasting discourses. The initial aspirations of the NPM were designed to develop discourses of professionalisation, managerialism, autonomy, responsibility, value creation, and quality. Instead, the prevalent discourses became focused on questions of financial control, efficacy, efficiency, standardisation, and measurement. It is important to reflect upon the complex domain of people's interests, which are challenged and re-shaped by discourses. This means that conflicting and contrasting aspects of the discourse may have implications for the organisation as a whole. Issues of identity are therefore worth considering more deeply, to understand recent changes in the Italian public sector.

Foucault argued that people tailor their own identities to fit their social context of reference. They accept or exclude ideas, reactions and behaviours, adopting mimicking strategies and looking at others' judgements to assess appropriateness or inappropriateness. This happens in line with implicit and tacit auto-imposed rules of living that we unconsciously impose on our neighbours through our own adherence to them. Identity is the result of a constant cycle of learning, unconscious mimicry, and automatic conformity to cultural frameworks. Foucault defined such cultural frameworks as 'regimes of truth' and argued that these allow self-recognition by fixing the boundaries of what will and will not be a recognisable form of being (Butler, 2005). These regimes identify the legitimate behaviours associated with cultural groups and prompt people to imitate actions to conform to the models to which they aspire. Chartrand and Bargh (1999) labelled this situation the Chameleon Effect. In essence, the practice of a culture becomes the expression of our identities. Individuals have an impact on others' identities, because every experience, interaction and reaction reinforces or modifies our own culture, and therefore the culture of others.

In the Italian public sector, the introduction of NPM has aggravated the neglect of individuals' identity and professional development. It has therefore brought about apparent changes, but these have usually been merely formal aspects rather than embedded in any substantive reasoning (Alvesson and Spicer, 2012). As a result, "everything remains the same" (Tomo, 2018), reinforcing discourses that cannot prompt long-lasting substantive changes.

Foucault (1980) stated that regimes of truth put forth dominant discourses (and rules) that govern what can be said, done and thought, inducing outcomes of power that in turn influence the dominant discourse. The "truth" is context- and time-specific and its circulatory nature is linked to both the systems of power that produce and sustain it, and the effects of power that it induces, and which extend it (Foucault, 1980). Power/knowledge discourses generate truth/s, and the rules that govern what is said and how it is said. However, the application of the rules is not always neat. The conditions, such as the interplay of discourses that produce possibilities for identities, are complex and slippery. Discursive rules allow certain identities and disallow others on the grounds that discourses can establish irrefutable truths by producing something real out of fiction. The consequences of a regime of truth are always twofold, because of a regime's intrinsic ability to enable something at the cost of constraining something else. This reflects the struggle to find a balance between these two. It inhibits the interplay of multiple voices, perspectives and narratives representing the interests and values of diverse groups (Baxter, 2002). These silences represent marginalised spaces, while the dominant assumptions remain unchallenged. 
Foucault (1990) articulated a possible form of reaction against this status in terms of resistance. He contended that discourse can be an instrument and an effect of power, but also a point of resistance and a starting point for opposition. Power creates points of resistance while producing dominant discourses that create discursive rules. It opens space for different identities. Foucault's studies are therefore particularly relevant for our purposes because he felt that subjectivity was important. He centred his views on the relationship between power and the self, on the grounds that any project of resistance arising against established power(s) must consider the process of self-formation (Munro, 2014). In his work on governmentality, Foucault developed the idea of counter-conduct, a neologism coined to differentiate his subjective conception of the relationship between power and resistance, and capture the interrelationship between protests and the forms of government they oppose. Counterconduct is rooted in one of the main Foucauldian insights: that power is relational, rather than being possessed or located. It is therefore a voluntary departure from ideas of revolt or dissent. It aims to conceptualise the multiple dimensions and inter-relationships of practices of both resistance and governance. Foucault focused on issues of pastoral power to show how movements emerged that asked in different ways: 'By whom do we consent to be directed or conducted? How do we want to be conducted? Towards what do we want to be led?' His counter-conduct view suggests that the negativity and destructivity of forms of resistance need to be left behind. It implies a positive view of resistance, because when discursive constructions are not questioned, regimes of truth merely act as ways to normalise behaviour towards disciplinary control.

Drawing on Foucault's perspective, we therefore attempted to understand how even potentially resistant public managers might generatively contribute to any change process if they are allowed to restate the macro discourses of the hegemonic NPM movement at their own micro level. The setting examined in this paper may well mirror the normalisation circumstances illustrated by Foucault, with public managers acting as passive recipients of the discourses of change. However, resistance to prevalent discourses informed predominantly by efficiency and measurement logics can also be generative. This happens when micro-politics of resistance, enacted by public managers aware of their struggle with the consolidated regimes of truth, are able to enforce identity reconstruction strategies. This paper taps into the dynamic interaction between the participants' self-identity and their identity work (see Alvesson and Willmott, 2002; Brown, 2017; Goretzki et al., 2013) in both their organisations and the training program. The participants were confronted with role models embedded in certain discourses (see Watson, 2008) and associated ideas. They could choose whether to identify with these, providing either aspirational identities (Thornborrow and Brown, 2009) or unwanted selves (Petriglieri and Stein, 2012). Focusing on their whole "adventure" allowed us to detect whether and how these public managers, in trying to resist unwanted selves, engaged in Foucault's counter-conduct. We also examined how this turned their resistance into a generative force rather than leading to a violent rebuttal.

\section{Research design}

We used a theoretically informed ethnographic approach combining semi-structured interviews $(\mathrm{Qu}$ and Dumay, 2011) with photo-elicitation and photo-voice (Warren and Parker, 2009), DiSC behavioural tests (Geier and Downey, 1989), and participant observation. We integrated these methods to provide a comprehensive understanding of public managers' role, identities, emotions and attitudes. This supported sensemaking of the overall phenomenon (Ravasi, 2017). The DiSC test aims to define individual behaviours and attitudes, providing a first description of individuals' identity through a series of prescribed categories (e.g., affable, analyst, individualist, involver, persuader, promoter, systematic, supporter) (see Tables 2 and 3). The interviews and photos led by participants 
completed the picture, and provided a description of participants' roles and identities, and how these are related to and influenced by specific prescriptions of the NPM regime.

The integrated methods provide a valid way to understand the social system of reference as a way to tap into the "becoming processes" (Parker and Warren, 2017) and perceptions of 29 public managers during a one-year publicly funded Executive Master of Public Administration (MPA) program. Materials and data were collected at the beginning and end of the training program over the academic year 2017-2018. The Executive Program was structured over five modules (16 hours per weekend across 20 weekends) and was conceived to be different from the past normative approach to change. It therefore promoted a new focus on behaviours and identity of change agents. It was conceived as an experiment and developed without any pressures from central government about the content and shape of the program. The scientific committee (consisting of professors of accounting, organisation, psychology, and law) had complete autonomy in designing the course, determining its objectives and establishing the lecture design and content. The program aimed to encourage fresh thinking on managerialism in the public sector, beyond the common stereotypes of efficiency, measurement, standardisation and conformity, and to develop a new understanding based on value creation, responsibility, accountability and performance. It was therefore specifically designed to be different from other initiatives, and have a strong focus on recovering human values, behaviours and identities, not limiting the vision to the classic accounting and management tools usually associated with NPMinspired training courses built around the concepts of efficiency and performance evaluation.

The participants were all public managers, and most had been working for 15 years or more in different areas (accounting and finance, human resources management, engineering and law). One of the authors is a member of the organising committee and tutored participants throughout the program, interacting with them and observing their reactions and communications during the lectures. The course was designed to devote two entire modules (120 hours from the total 320 hours) to behavioural and team building training under the mentoring of two psychologists. The researchers therefore observed the interactions during these modules. The overall ethnographic approach was enhanced by the researchers' lengthy involvement in training as well as research projects on public sector environments carried out both in Italy and abroad.

The first step of the data collection used the motivational colloquium conducted during participant selection and the results of the DiSC Behavioural Test (Geier and Downey, 1989) carried out at the beginning of the course. The colloquium was convened by three members of the scientific committee of the MPA, one of whom is an author of this paper. The motivational colloquium aimed to assess participants' reasons for applying for the training, their expectations, whether they occupied influential positions within their organisations, and how they managed their role. The conversations were not recorded, but we used the notes taken by the three members of the committee about the participants.

The DiSC assessment is used by psychologists to understand the complexity of interactive forces responsible for behaviour. It helps people to understand themselves and others showing the range of normal human behaviour (Motley and Hartley, 2005). It focuses on specific behaviours/traits such as dominance, influence, steadiness, and conscientiousness, using a scale. Individuals have varying degrees of each trait, and research indicates that most people lean primarily towards one or two traits. DiSC provides evidence on how individuals respond to challenges, how they influence others, how they respond to rules and procedures, and their preferred pace of activity.

DiSC tests were administered to the participants at the start of the lectures by one of the researchers. Participants were told why this tool was used and how to complete the test. They were given the results and had the chance to discuss them with two psychologists. The DiSC test alone is not 
sufficient to identify all the nuances of personality. However, it was an informative starting point, and taken with the insights from the motivational colloquium formed the basis for the next steps in the study, involving semi-structured interviews which took place before and after participants' attendance at the program. It also allowed a deeper understanding of the type of change (if any) in participants' identities caused by their involvement in the training course. This assessment of participants' characteristics was also useful to tutors and lecturers for interpreting the behavioural posture of participants during the activities.

The second step, following Warren and Parker (2009), involved a theoretically informed ethnographic approach based on a hybrid strategy, combining in-depth verbal interviews with the use of photoelicitation to increase the participants' control of data generation and observations (Parker, 2009; Parker and Jeacle, 2019). Photo-elicitation offers additional tools for contextualised, interpretive and critical discovery in accounting and management (Parker, 2009) and generates spoken narratives (Parker and Warren, 2017) suitable for researching intangible aspects of an individual's work life, and cultural and world views (Parker and Warren, 2017). Photo-elicitation enables researchers to give voice to participants' constructions and meanings that would otherwise remain hidden (Parker and Warren, 2017). Warren's (2005) approach to visual research uses images and imagery to help participants express their feelings, beliefs and opinions either as an aid to or instead of a verbal narrative.

The aim was to understand the social system of reference of the participants, to tap into their identity construction processes and perceptions of their role in their working context. The use of pictures allowed the researchers to talk freely because the interviewees used the images to emphasise positive aspects and distance themselves from undesired situations, ensuring a deeper analysis of the phenomena than would have otherwise been possible. The semi-structured interviews with 29 public managers followed an agenda of topics to be discussed rather than a structured set of questions. They lasted about 90 minutes in total for the two interviews with each participant. The interviews aimed to build a more in-depth picture of how interviewees felt about their roles, their organisations' role in the wider institutional context, and the skills, routines, practices, and management tools acquired during the training program. The interviewees were asked to bring photographs, pictures or images. Participants were asked to freely choose images from personal photos, photos taken at the workplace, reproductions of paintings, images taken from the internet or any other image/picture that represented their views of the relationship between their role as public managers and their working context. This approach, consistent with Tomo and Spanò (2020), was motivated by the researchers' concern to allow participants to tell their own story, reducing any possible perceived emotional stress. This allowed us to take full advantage of participants' self-selection and/or creation of the image and the message that it conveyed (Warren, 2005).

We provided participants with instructions to make sure they understood their role in creating, selecting and discussing the image (see the appendix for the details). The interviews were digitally recorded, and then transcribed for analysis. A follow-up interview was conducted if any data were unclear. The interviewees were asked to review the transcripts and make any corrections.

Table 1 provides a profile of the participants interviewed. 
The third step of the analysis took place at the end of the course. We repeated the DiSC tests and interviews with all the participants. We integrated the information from this with data from several occasions on which the research team observed the participants in action. The purpose was to identify any changes in their feelings, emotions, reactions, and perceptions.

Information gathered through interviews was triangulated with data drawn from the other sources. Using participants' responses, we attempted to explore and understand their views on organisational change, individual change, and any space for synergic positive changes. The pictures were analysed as 'visual data', but also used as a vehicle to generate narratives, and were therefore an integral part of the material analysed (Warren and Parker, 2017). Once all the interviews had been completed, the researchers organised the transcripts, and started to trace relevant issues. All the transcripts were inductively analysed by one of the researchers to identify major themes. A second researcher then reviewed all the material to identify and confirm relevant themes and concepts and categorise the content into theoretically relevant categories. This also allowed us to detect emerging/unexpected themes, which enriched our analysis and provided interesting questions for further inquiry.

For reasons of space, we limited the extracts reported from the 29 interviews by following the suggestions available in the literature (e.g., Alvesson and Ashcraft, 2012; Saunders and Townsend, 2016). We therefore selected the extracts representing the most recurrent DiSC categories and provided enough coverage through variation among interviewed participants by considering how they switched from one category to another. We chose to report cases that represented different types of public administrations. The reported examples therefore provide both varied cases and insights from different contexts, including three central government (e.g., Ministries) and three local government administrations (e.g., universities and local branches of social welfare institute).

\section{Findings}

This section starts by analysing the characteristics of the participants at the beginning of the training program and their prevailing regimes of truth. It then explains the structure of the program, the meanings of the initiatives taking place, and any intermediate responses of participants to the stimuli from the program. Finally, it covers the characteristics of the participants at the end of the training program, acknowledging that in their professional roles, they are embedded in discourses that shape certain regimes of truth that define their behaviour and are used as a form of self-discipline. We then consider whether and how participants' reflection on and interpretation of their regimes of truth changed, and the implications for their performance and perceived identity.

\section{Participants' characteristics in the early stages}

Table 2 shows the distribution of participants by DiSC test categories, highlighting the predominant traits. It summarises views emerging from comments on the images, matching them with the DiSC characteristics. At the start of the program, there were three common personality traits. The first was the analyst (nine participants), who show characteristics of rigidity and loneliness, and perceive changes as something to be dealt with ceremonially. The second was the persuader (five participants), 
who show a selfish perception of superiority and self-perceived ability to manage everything easily. The final trait was the individualist (four participants), who deal with contrasting emotions and show strong perceptions of uncertainty and insecurity.

\section{TABLE 2}

The images and comments were often consistent with the profiles emerging from the DiSC test. Some examples are provided to illustrate participants' feelings and the general picture of the regimes of truth informing those involved.

One of the participants, falling into the 'analyst' category (characterised by rejection of personal aggression, correctness, logical and critical approaches, worrying and sometimes irrational behaviours), provided a revealing image (Figure 1) with extensive comments.

\section{FIGURE 1}

The image represents a woman sitting at a window who looks sadly outside, imagining a whole world 'out there'. She feels blocked and rigidly fixed in the chair. She is looking for her face, her identity, her feelings and emotion. She needs to open the window, but she does not feel ready to go outside into the world. This is the way I feel when I look at my changing tasks. I feel uncomfortable with my role, as I look at a fast-changing process in my work, but I feel unable to go as fast as I should. I feel scared and lonely. I would like to do better, and I hope that the training will show me the way to go outside in this mad world. (Participant \#24).

Another participant, categorised as an 'individualist' (characterised by acceptance of personal aggression, a search for the unusual, a focus on standards and initiatives to bring changes, overly critical approaches, inconsistency and little ability to influence others), provided another image (Figure 2) consistent with their profile. Their comment is below.

FIGURE 2 
The image represents an indecisive person, who would like to fly away but is kept on the ground by a strong force. A person willing to bring change, but incapable of fostering it. A personality divided between yesterday and tomorrow. I feel divided, and I believe that the greatest enemy of change is not "no", but "not yet". This is why I now feel uncomfortable with my role, and so uncertain. (Participant \#15).

Participant \#27 was categorised as 'affable', and experienced significant confusion about the ongoing changes in his workplace. He explained his views in functional terms of efficiency, symmetry and perfection. He showed a picture of a typical Italian garden (Figure 3), characterised by tough and perfectionist harmony, in strict conformity to a predetermined order. He argued that "in this environment there is no space for one's initiatives and for the unexpected. Things happen and are admitted only if they do not deviate from the standard and the planned course of action".

\section{FIGURE 3}

A further example emerged from the interview with Participant \#9, categorised as an 'involver', and showing profound emotional involvement in change. She showed openness and positive anticipation of change but felt unable to fully achieve the associated expectations. Her picture is a famous photo by Rodney Smith "Kelsey Balancing on Tightrope" (Armenia, NY), which represents a woman attempting to find balance on a wire located between two high hedges. The participant commented: "I am curious to have a look beyond the hedge but despite my effort to keep moving and stay in balance, I cannot see what is beyond that because I do not have the necessary tools".

The majority of participants declared themselves to be nervous about the process of change, and uncomfortable about the forthcoming challenges. However, they were also willing to engage with the training program. They acknowledged the complexity of their field, and some had reservations about the course's potential usefulness. They therefore started the course with many doubts and a sense of impotence. These people conformed to regimes of truth centred on the idea that people are simply $\operatorname{cogs}$ in a machine that aims to deliver financial objectives. They felt compelled to focus on efficiency and avoid any deviation from the "standards". This view appeared to restrict any enhancement of their managerial attitudes and responsiveness to innovation in service quality and efficiency. This regime of truth appeared to be widespread and affected participants' approaches independently of the type of public administration. It was complemented by some additional aspects highlighting different ways in which people handle and deal with the dominant discourses.

At the outset, some participants presented a self-centred attitude, appearing concerned to demonstrate their superior abilities to manage everything correctly. They often behaved impatiently and manipulatively during the first meetings. This happened when participants had some previously acquired knowledge of management issues, either from previous training or from their job. A pertinent image (Figure 4) was provided by participant \#7, a persuader. He shared these views but often attempted to demonstrate forcefulness and courage, projecting a message suggesting a willingness to crash through any externally imposed limits, for example exhibiting facial expressions that researchers interpreted as meaning "I can do it, I am not afraid". 


\section{FIGURE 4}

The work group leading the training course therefore used the composite and integrated strategy explained in the following sub-section. The aim was to foster a discursively and mutually agreed change in participants' attitudes and approaches and a process of identification enabling a clearer understanding of the raison d'etre for the changes, and participants' ability to interpret the change within and for their organisations. This approach was agreed before the selection of participants and refined to reflect the profiles emerging during the first phase.

\section{Evolving Program Structure}

The training program was built around five modules, each lasting four weeks, and a total of sixteen hours across three days each week. The first two modules were about relational and behavioural aspects. The training program was designed to encourage individuals to work on themselves and their identities in the absence of prominent regimes of truth and views specifying what was correct/not correct and allowed/disallowed. The program was therefore specifically developed to avoid constituting any new or alternative regimes of truth for participants to adhere to or avoid. Far from imposing a specific kind of identity, the program was intended to improve participants' reflection upon, and interpretation of, regimes of truth, how these may change and how they can deal with the changes by focusing on performance, self-discipline and perceptions of self-identity. The team therefore accompanied participants on a journey of exploration of their personal selves, their identities at work and the relationships with people they trust or with whom they are forced to engage and understanding how their own and others' selves may be shaped and shape an organisation through interactions with other people within working groups. The first phase of the training program highlighted the different roles of individuals within working groups and analysed the complexity related to leadership dimensions. These behavioural modules were therefore different from other training initiatives because they helped participants to develop a different perspective on the accounting, management and organisational tools that were the main content of the other three modules of the training program. These modules were key in providing a unique and distinctive training path to participants.

The process of exploration of the "self" aimed to build self-awareness of individual strengths and weaknesses and develop flexibility and adaptive skills. These processes were carried out through focus groups among four or five participants, to simulate meetings and specific conflict situations, and to scrutinise ways of handling these situations. During and after these activities, participants were asked to reflect in a group about their organisations and their roles, analysing at a deep emotional level how they build and manage relationships at work. This also included a re-thinking of the role of accounting and management tools, going well beyond the perception of them as instruments placing excessive pressure on public managers' administrative action in terms of performance and efficiency. This pressure had led to two main biases: a complete disconnect from the outcomes for 
citizens, because of an excessive focus on the tools themselves as "final goals", and loss of the relational and behavioural dimensions within public organisations.

The aim was to prompt participants to accept and openly challenge themselves to attempt something new even if they could not initially understand the rationale or the possible benefits. This triggered resistance and conflicts, not only among participants, but also between some of them (usually persuaders or individualists) and the trainers. These critical moments were mainly caused by the characteristics of the first two modules, and especially their focus on individual beliefs, values and identities. This dimension is one of the main reasons why managers tended to show heterogeneous behaviours. Some participants easily accepted the process of challenging themselves, but others found it harder to handle and revise their deep-rooted beliefs and values. To overcome these difficulties, the trainers spent more time and effort with resistant participants to analyse with them the aims behind the activities, the expected outcomes, and ways to resolve any areas of dissatisfaction with the structure of the course. The trainers themselves were also often under pressure because they sometimes felt that their role was not fully recognised or was unfavourably perceived by participants. This required more effort to build an open-minded relationship with all participants. However, by the end of the training program, even the initially resistant participants had acknowledged the relevance of the activities and asked for similar experiences. The active role of trainers in "playing" with participants, sharing with them the rationale of the program and spending time with each participant on a one-to-one basis when needed, improved participants' understanding of the ideas behind the program. This helped the majority of participants to reach an awareness that there is a whole community of people who are willing to understand and share their feelings, emotions, and challenges and move towards a more conscious and less submissive approach to NPM change. This provided a fundamental basis for empowering participants to engage more proactively in the subsequent activities of the program.

At the end of these first two modules, participants were asked to develop a report on the activities. They voluntarily decided to use a visual approach and organised a small exhibition of pictures and images to give voice to their feelings. They invited the trainers, organisers, and friends and relatives to share their personal and emotional pathway.

The work group also attempted to improve participants' ability to manage unexpected events and rapidly changing programs. Participants had to manage changes to planned activities, and were given unexpected tasks to solve within a defined length of time. They also had to cope with specific teaching requests. These choices were deliberately not fully explained at the outset, to foster adaptability and flexibility. This sometimes generated resistance and criticism, but over the program these became the basis for proactive reflection.

Particular attention was paid to making participants feeling comfortable with the accounting tools and techniques useful for their tasks, encouraging renewed awareness of these tools and enabling proactive engagement. The set of tools proposed was quite heterogeneous and based on two main ideas. The first was the importance of providing participants with technical skills for techniques that have already been proved relevant for public management, but also introducing them to tools with some multidimensional (not strictly quantitative) characteristics, and explaining their underlying logic. Accounting-related sub-modules of the training program therefore touched on issues of cost accounting and cost-benefit analysis, and how to manage circumstances in which measurement of performance is not clearly and objectively identifiable (using simulated cases of museums, healthcare organisations, and universities). This very first attempt to make traditional accounting more accessible aimed to improve participants' awareness of the meanings and consequences of accounting numbers and related choices, and unveiled interesting dynamics. 
The reactions of participants to this "playing with numbers activity" showed trajectories of contrast and then convergence on a new understanding of accounting, featuring the typical characteristics of counter-conduct. Some participants - the purists-were already well-equipped with a specific set of accounting competencies and skills. They were reluctant to approach this dialogic and to some extent 'elusive' perspective of accounting. However, individuals who were usually hesitant about accounting and its 'impenetrable secret', acknowledged some unexpectedly more relaxed and trusting perceptions of accounting tools. These contrasting/converging reactions were discussed and analysed. Alongside hybrid teams, this progressively fostered a greater awareness among both groups of participants that was evident at the end of the program. The 'purists' in particular finally recognised that: "looking at the numbers as 'pure numbers' distracts from looking at the numbers as something that results from 'human action and interaction"' (Participant \#1). Reluctant and hesitant participants understood that "if accounting is understood as a language for negotiation and not as a coercive punishment device, it has room to affect organisational decision-making" (Participant \#9).

Secondly, more complex and holistic approaches were subject to debate and experiments, including Business Process Re-engineering and the Balanced Scorecard. Participants were given descriptions of these tools' characteristic technical features, and then discussed crucial and more complex aspects relating to their non-financial and less quantitative dimensions. Time was also spent highlighting and debating why and how these tools shape and are in turn shaped by aspects of human behaviour, and whether and how they are likely to affect and be affected by individual and organisational relational dimensions.

Many of the participants had been familiar with more traditional accounting tools, but this part of the program was quite new for all of them. There was a common impression of favourable surprise about the potential of these holistic approaches. Interestingly, participants already familiar with accounting acknowledged that by considering their new perspective on the meaning of accounting in organisational decision-making (beyond mere numbers), they could see more holistic approaches in a new light. One participant clarified this aspect very effectively.

I never thought of the Balanced Scorecard as a useful tool to understand the human dimension of the organisation. I never used it, because I thought it was exaggerated and too complex for a public sector organisation. I have always looked at it as a fashionable tool for private companies...but then I realised that I was missing the point that public administrations are also made up of people...I was too worried about efficiency targets, and was prone to see numbers as something taken for granted...I must confess that I see a totally new potential in trusting tools like this, which I have previously avoided as passing fads. (Participant \#1).

For other participants, analysing these tools offered the chance to ground and apply their changed view of accounting within organisations in practice, strengthening their new feeling of trust.

None of these interventions attempted to impose any specific type of identity. The aim was to encourage reflections among the participants. There was some initial resistance, but this approach soon resulted in greater awareness about accounting tools, their underlying logic, and their contextual relevance within organisations. In summary, and as the next sub-section will show in more detail, over the last three modules, and at the end of the training program, participants became more secure and less stressed about approaching managerial and accounting tools. Some participants specifically remarked that the training program provided them with a new perspective and a toolbox to face the challenges and uncertainties posed by their everyday work. 
Instruments such as budget and balanced scorecard have always stressed me... I felt oppressed by these tools, they seem to constantly remind you what you have to do and when ... it's like a warning light in your car that puts pressure on you. Now I have a different feeling, I am more conscious of these instruments' role and the relational implications they have on the whole organisation. It seems now I have a clearer picture of their functioning and meaning, and this makes me feel calmer. (Participant \#9).

In the light of their experience of the first two modules, participants approached the tools from an entirely new perspective than their previous experiences within their own organisations. They could tap into relational and motivating dimensions of performance management that went far beyond the meaning, limits and consequences of "counting numbers". This fostered a slow but effective (re)discovery of the human dimension of tools and techniques, and an awareness among participants of a mutual influence between instruments and behaviours. Interestingly, some of them revealed that this is something that they implicitly already knew, but that they tended to disregard in their everyday life, partly because of the pressure to pursue strict quantitative objectives (such as cost targets) under NPM within their organisations.

The program was a fundamental approach to these issues, because it involved participants in simulations and abstractions to enable them to explore new and modified applications. It also supported scrutiny of individual behaviour and emotions. Essential elements were cooperation and open dialogue during group activities to simulate realistic circumstances and explore possible decision-making processes, as well as mediation and conflict resolution. These aspects were not initially explained to participants, so they were subject to initial scepticism and criticism when participants found themselves in an unusual training context. However, later, the new (re-discovered) dimensions were progressively understood and internalised.

\section{Participants' late stage characteristics}

Table 3 shows the distribution of participants by the DiSC test categories, indicating the predominant traits and summarising the views emerging from comments on the images, matching them with the DiSC characteristics.

\section{TABLE 3}

The images and comments were generally consistent with the profiles emerging from the DiSC test. The program produced many changes in the attitudes of participants, who often moved from one category to another, showing greater heterogeneity than in the initial stage. The exploration of the relational and behavioural dimensions also provided a new way of looking at accounting and management tools. Participants' re-focused perception of self allowed them to look at the instruments as ways to support their activities, rather than as producers of stress in their role as performance indicators. The increased consciousness about themselves and their approach to accounting and management tools removed or reduced rebuttal and produced a different type of resistance. Resistance here showed particular features and empowered self-renaissance of individuals. They progressively 
started to re-focus approaches starting from their own identity and avoiding any deliberate opposition to change without considering whether and how it could be turned into an opportunity.

Participant \#24, initially categorised as 'analyst', switched to the category of 'empathiser' during the course, showing positive acceptance, more openness in personal relationships, ability to listen, patience and tolerance. His comment on the image (Figure 5) gives an idea of the impact of the program.

\section{FIGURE 5}

The image represents a crowded street where I am walking together with other people. I am progressively discovering who I am, and I feel able to confront all of the other people, going further in my pathway to build relationships. I am now self-confident and, above all, quiet. It is a big change if you think that, almost one year ago, I was feeling totally blocked and scared of the world outside. I must confess that I hoped that the training would show me how to operate outside in this mad world, but what I got was actually much more than this. (Participant \#24).

Participant \#15, initially categorised as an 'individualist', changed to the category 'specialist' by the end of the program. This category shows more moderation, focus on relationships, an ability to plan and maintain pace, and consistent performance, despite still being concerned by change in terms of disorganisation. The comment about the image provided (Q. Buchholz, "Man on a High Wire"), showing a man attempting to balance on high voltage wires in fog, mirrors the new characteristics of the participant's identity after the program.

The image represents a new adventure, a new reality to face... I can't wait to start this new way but sometimes it seems that due to the disorganisation of the field it takes more time to begin. I am no longer divided between yesterday and tomorrow, but I still struggle to find a balance between the necessary change to pursue, and the disorganisation that the change involves. I believe that only by consistently planning change will it truly work. I think that the training has helped me to understand that I cannot control everything and that being adaptable and flexible is the key for long-lasting changes. I still have not reached these ambitious goals, but I will put more effort into this pathway. (Participant \#15).

\section{FIGURE 6}

Interestingly, participant \#27, who was categorised as 'affable' at the outset, had changed by the end of the course to match the traits of the category 'producer'. This person's apparent body language also mirrored this change. The picture (Figure 6) shows a typical English Garden, very different from the initially presented Italian one. He commented as follows. 
I would represent myself as an English-style garden where plants, not cultivated, alternate in a less rigidly defined order and mingle with self-seeded plants brought here by the wind. Here the environment forces us to weave continuous relationships with the different elements involved. Thanks to the training course I learned to understand the context around me, and its rules (or absence of rules). A small ecosystem, to be observed even where it is less obvious, so that it reveals its nature and can be transformed starting from the relationships within it.

We did not notice any revolution in participants' professional identity, but we did see a progressive enrichment of the self and a more proactive approach to the change. Participant \#9, who switched from the category 'involver' to 'promoter', was an example of this personal growth. Initially, she was open to change but suffered because of her inability to look beyond the hedge. At the end of the training course she felt she had obtained an indispensable toolbox, especially of soft skills, to improve her relationships. The participant showed a photo by Rodney Smith "A.J. Looking Over Ivy-Covered Wall" (Harriman, NY) commenting that like the man in the image, she now can look over the wall thanks to the ladder offered by the program. She now looks "... at the beautiful chances that wait outside. The ladder represents my professional and personal pathway, which is not yet ended, but no longer stopped, as I now have tools that I will use in the foreseeable future".

Another participant offered us the chance to tap into her profound emotional experience. When this interviewee came to the last interview, she brought the same image as at the beginning of the course. The picture (Figure 7) shows a blindfolded woman in a cloud covered location close to the sea. At the beginning of the course, the participant was categorised as an 'analyst' and her description of the picture epitomised the aspects of rigidity and loneliness that characterise such a category. She initially described the picture by stressing the sense of melancholy and unsafe situation of this woman who cannot see the storm which is likely to come and therefore cannot protect herself. By the end of the course, this participant had switched to the category 'deducer', showing much more serenity, selfconfidence, and a renewed and re-evaluated attitude to her work. We were therefore quite surprised when she showed the same picture. However, when she was asked to comment on it, she cited Francis Bacon stating that "If a man will begin with certainties, he shall end in doubts; but if he will be content to begin with doubts, he shall end in certainties."

\section{FIGURE 7}

She clarified that she felt the same person, because she had never allowed work dissatisfaction to affect her inner self. However, the course had showed her that even if she sometimes feels blind, this is not necessarily a limitation. Instead, it may mean that she can strengthen and further develop other senses to be ready to achieve her goals. (Participant \#19).

There were some nuances, but the majority of participants declared themselves to be more open to change. They felt more comfortable with the challenges they faced, and were willing to start to apply their newly acquired logics to these tasks. Many also acknowledged that they now felt more comfortable with the complexity of the field. Some switched from suspicious and reticent approaches to a more enthusiastic and value-driven willingness to foster collaboration and integration within their organisations, and were interested in becoming change ambassadors for something new and positive. Change and complexity were no longer threats but became opportunities, not only in their work, but more importantly in terms of life experiences and relationships. This changed rationality was so 
significant that the participants have now strongly supported the creation of an alumni association for the program. This association has two aims: maintaining the vitality of the new approaches among participants, and helping them to become ambassadors outside the boundaries of the course for a renewed view of their role in the field, prompting progressive improvement among other people. At the beginning of the course, some participants presented a strong self-perception, and were concerned to demonstrate their superior abilities to manage everything correctly. They often behaved impatiently and manipulatively. However, by the end of the program, this behaviour had almost disappeared.

These results allowed us to identify a switch in the prevailing attitudes and discourses of the program participants. There was a change from a strictly financial logic to an awareness of the importance of value-oriented behaviours. People considered their professional identity in much less restricted ways and began to consider themselves as enablers. They no longer saw their work as a result of the formal organisational structure. Instead, they recognised their potential to craft a brand-new organisational structure going beyond conformity, to creatively affect and influence policies and procedures. Overall, participants felt better able to achieve value through efficiency, which for them had now become a means to an end rather than an end in itself. This was mainly caused by the relational and behavioural modules within the training program, which gave them a new understanding of themselves and their way of seeing and approaching accounting and management tools. Before the program, these tools often represented an "identity cage" made of efficiency and pressure for performance. This blocked their ability to be "individuals" within the organisation. The program enabled participants to recover a view of themselves as individuals within a context made of relationships and not merely techniques, rules and operational manuals.

\section{Discussion and conclusions}

This paper has sought to engage with the discourses informing NPM and to reveal how change is introduced and experienced by individual managers in the process of a public sector change management program. This level of change management and experience has been neglected in prior NPM change research, which has focused largely on societal and organisational levels. We were interested in understanding the micro-politics behind change processes, and specifically to understand how public managers interpret and convey change to the organisation as active agents rather than passive recipients.

Our study of individual managers used Foucault's conceptualisation of 'regimes of truth' as its theoretical lens. This supported the understanding of how a change in the discourse and regimes of truth may lead to different responses, potentially fostering what Foucault called counter-conducts, and turning rebuttal towards more generative kinds of resistance.

This study has explored the peculiar context of the Italian public sector. Over the last 30 years, there has been a national intention to improve public sector efficiency and effectiveness by enhancing the professional skills and performance of individual public sector managers. However, the increasing concern to achieve short-term efficiency at any cost (even if it compromises quality of service delivery) and to measure everything, has instead led to greater standardisation of practices and procedures and to a subsequent individual "identity cage" (Spanò, 2018; Tomo, 2018). Our data analysis drew on a theoretically informed ethnographic approach based on a hybrid data collection strategy combining 58 in-depth verbal interviews with the use of photo-elicitation, DiSC behavioural tests, and participant observation. This methodological choice allowed us to tap into the "becoming 
processes" and perceptions of 29 public managers during a 12-month advanced management training course at an Italian university.

Foucault argued that identity is the result of a constant cycle of learning, unconscious mimicry, and automatic conformity to normative cultural frameworks that become the frames of reference for interpreting experiences. In line with this theoretical argument, in our study's Italian setting, it is possible to recognise a nationally consolidated public sector discourse under the NPM umbrella of financial control, efficacy, efficiency, standardisation, and measurement. This has neglected individuals' development and identity-related questions, undermining the prospect of any substantive changes in public sector management. Focusing on this, and the emotions and perceptions expressed by participants during the study, our findings offer several interesting insights.

The interviewees often referred to nervousness, discomfort, scepticism, but also enthusiasm for the new adventure. They often cited the widespread confusion and complexity of the sector as a major factor that could limit the usefulness of the course for their everyday work. The range of perceptions and feelings from the study, together with the insights gained into characteristics through the DiSC test, allowed us to understand the prevailing discourses at the beginning of the training period. The prevailing regime of truth that emerged was a mechanistic view of organisational life that undervalued people's identities and qualities in favour of efficiency-focused standardisation and demanding financial objectives. This regime of truth appeared to limit managers' initiative and strategic responsiveness, and induce self-centred reactions and manipulative behaviours from managers who were attempting to distance themselves from the organisation and its objectives.

Foucault (1980) admitted that dominant discourses are not irrefutable, and that resistance may well open up space for new, alternative individual identities. Foucault advanced the idea of counterconduct on the basis that power is relational, rather than being possessed or located. He therefore suggested that the negativity and destructivity of forms of resistance need to be left behind. Foucault's firm conviction was that resistance can be functional and productive. This is because when discursive constructions are not questioned and are taken for granted, regimes of truth merely act as ways to normalise behaviour towards disciplinary control. This normalisation in the Italian public sector has arguably neglected public managers' identity questions, which has rendered them passive recipients of the discourses of change, left to resist top-down imposed logics in dysfunctional ways. This dysfunctional resistance appears to have been induced by the prevailing regime of truth, which has emphasised efficiency-focused standardisation and demanding financial objectives.

However, our findings are consistent with Foucault's (1980) positive view of resistance as a generative force. The results allow us to understand how changing the discourse and the consequent regimes of truth through a program centred on identity construction may lead to different responses. This then unveils counter-conduct dynamics, with resistance turning into a generative and enabling force that can elicit more relationally and negotiated solutions of change. We found that changes in the discourses and the resulting regimes of truth led to public managers changing their perceptions of themselves and their work. This is arguably a basis to expect different and new attitudes towards change, which will probably be taken back to the organisations.

Focusing on the program structure, we can better understand whether and how the program activities fostered any changes in the regime of truth. The program relied upon a process of exploration of the "self" to build self-awareness and develop flexibility and adaptive skills. The strong relational focus was essential to prompt open dialogue and debate among participants. The program also challenged them to address fears and overcome resistance, even when trying to manage the unexpected. This process involved the creation of a set of skills and capabilities to familiarise participants with potentially useful managerial tools and techniques. By using simulations and abstractions, the course 
aimed to make participants aware of the potential of these tools, rather than presenting them as mere compliance requirements. Many of the activities undertaken during the course elicited strong reactions and resistance from some managers. However, the researchers involved in delivering the program embraced these episodes of resistance as opportunities to provide a more profound understanding of the opportunities of change. In other words, resistance was generatively employed to empower individuals to turn themselves from being passive recipients, to acting as proactive change agents capable of developing and articulating generative resistance in their own organisations. This therefore offered a renewed approach to individual and organisational change.

At the end of the program, these approaches appeared to have produced observable outcomes among individual managers. Participants appeared to be more open to change. Many made a more conscious acceptance of the elements of complexity they faced, but switched from reserved to more positive stances. They were also better able to reflect upon and mobilise their own values, drawing upon those to help them act as change agents in their own organisations, presenting change as a potential opportunity. This shift in posture laid foundations for a new impending regime of truth, focusing on value-oriented behaviours rather than strictly financial logics. It also showed that public managers can act as enablers, and influence the organisation, rather than being passively shaped by it, redefining efficiency as a means to an end, rather than the end in itself. The program was neither a panacea, nor superior to other training programs. However, it was different from traditional public sector training programs that have to date been more centred on tools and outcomes. Instead, this course offered managers space for soft skills development and reflecting on and re-thinking their roles and identities within an organisational setting.

The findings are valuable because they offer a multifaceted contribution to the research on accounting and management change. Firstly, the paper acknowledges the significant imbalance between organisation-centred studies and individual-centred studies (Brown, 2019). It therefore offers a novel approach to individual-level analysis. In doing so, it contributes towards a more individually sensitive inquiry into how change processes take place (Jacobs, 2005; Liguori and Steccolini, 2014), instead of focusing merely on what changes are implemented. The analysis complements and expands on previous studies (Broadbent and Laughlin, 2013; Fiondella et al., 2106; Spanò et al., 2020) in addressing the severely polarised debate on the outcomes of change understood as resistance or hybridisation and success (e.g., Broadbent et al., 2001; Gurd and Thorne, 2003; Abernethy and Vagnoni, 2004; Jacobs et al., 2004; Kurunmaki et al., 2003; Kurunmaki, 2004; Kurunmaki and Miller, 2006; Mir and Rahaman, 2006). Its focus on change agents, and how they understand, interpret and convey change, highlighted a more nuanced landscape between these two extremes (Blomgren, 2003; Kärreman and Alvesson, 2004; Sveningsson and Alvesson, 2003; Watson, 2008, 2009). This may therefore foster greater acceptance of change (Broadbent and Laughlin, 2013).

The paper confirms Jönsson and Solli's (1993) view that organisational learning and training pave the way for closer consideration of identity construction issues, as a key to effective change. It also shows how discourses of this kind can turn resistance into a generative rather than destroying force. The study also adds to the conclusions of Carlsson et al. (2016) and Spanò et al. (2020). Both these papers suggest that a profound understanding of the new logics within organisations and the engagement of individuals are essential to make individual stakeholders into partners in any change process. This study also showed how discourses centred on identity construction and the resulting regimes of truth are crucial supports for cultural change. Clearly, and in line with Goretzki et al. (2013) and Hay et al. (2020), this paper shows that identity construction-based discourses have the potential to validate instead of challenge individuals' emotions, perceptions, and self-awareness. This may encourage them to become business partners in the change. Collaboration and knowledge sharing can create a liminal space that allows professionals to learn new tasks and engage in identity restructuring. The findings also offer fresh insights into the debate about the micro-politics of identity 
construction (Brown, 2015; Allain et al., 2021) and how they may have meso and macroconsequences.

Beyond these contributions to the literature on management and accounting change, the paper offers an important foundation for reflection on NPM. We suggest that our findings are fundamental to a renewed understanding of the failure of NPM as an identity project, and why this has led to unsatisfying results and unsolved identity issues (Kärreman and Alvesson, 2009). The paper offers a contribution to the stream of research about the ways in which identities are enmeshed in relations of power, the micro-politics of identity formation, and issues of structure and agency (see Brown, 2019), which is still largely overlooked in the public sector literature.

The findings show that embracing public sector managers' identity-related issues could generatively influence resistance or rebuttal of change and move it towards more relationally and negotiated solutions. Public managers and employees may experience situations of "going through the motions" (cynical approach), alienation, dis-identification, or detachment from the identity imposed by the administration ("this is not me") (Costas and Fleming, 2009). Our in-depth analysis improves understanding of the discursive forces that may shape public managers' difficulties in adapting and transforming their identities, often seen as major causes of failure (Costas and Fleming, 2009; Liguori and Steccolini, 2014). The paper therefore shows how even potentially resistant public managers might generatively contribute to change when they are given the chance to restate the macro discourses of the hegemonic NPM movement at their own micro level. It highlights processes in which public sector managers do not fully subjugate themselves to NPM agendas but also do not fully resist them.

Our findings expand upon the idea set out by Allain et al. (2021) that resistance does not necessarily have dangerous consequences for either those promoting change (dismantling it) or those resisting it (further strengthening the neoliberal dynamic of the reform they wanted to avoid). Instead, identitycentred discourses can turn resistance into a potential enabler of greater acceptance of change (Thomas and Davies, 2005). We saw how public managers turned from being passive recipients into active agents of change, living a transformation at a deeper emotional level, with feelings such as discomfort and dissatisfaction transforming into progressive acceptance and openness. This phenomenon has important implications, because it exposes 'tools' that may be useful for converting resistance towards a more generative approach. Following the suggestions by Barratt (2008), we have therefore contributed to an alternative Foucauldian political view of the workplace, based on "an assessment of actual possibilities and political conditions" (p. 534). We have expanded the generative resistance idea of Thomas and Davies (2005) to address how different behaviours are enacted. Our paper also shows a type of resistance (positive and generative) that can reduce counter-resistance from the organisation, because initiatives and actions are built on discourses around autonomy, engagement and commitment (Kärreman and Alvesson, 2009).

The paper also offers a methodological contribution, by using a combination of photo-elicitation, photo-voice and DiSC behavioural tests to gather as much data as possible. This allowed us to identify and triangulate multiple behavioural characteristics and social systems of reference involved in individual processes of self-reflection, value modification and identity change. This therefore fits with calls for wider research approaches using visual sources, which have still only been used in a fairly limited way (Runfola et al., 2017; Skjælaaen et al., 2020). The use of the visual approach in this study encouraged openness by interviewees. A "thinking out loud" message allowed participants to feel more comfortable in commenting on their emotions and points of view. The use of multiple image sources provided by participants, ranging from found to self-created images, could be viewed as a limitation because of the mixture of sources. However, these can also be considered as credible sources voluntarily provided and commented upon by participants wishing to reflect upon and express 
their own perceptions, experiences, and values. In studies of individual change processes, this method appears to offer considerable promise for deepening researchers' encounters with, and understandings of, individuals' attitudes and behaviours (see also Ravasi, 2017). This contribution also encourages methodological diversity in qualitative management research, contrasting with attempts to homogenise experience and reporting (Cassel, 2016).

This paper also has implications for policy and practice. It provides a basis for evaluating how and to what extent regulatory entropy affects public managers. It calls for more effort to mitigate the risks of failure in reforms associated with this phenomenon. Regulatory entropy has been seen when public sector managers feel threatened by efficiency and financially constrained regimes of truth. Instead of promoting the public sector values of trust and accountability, they are tempted to withdraw into a self-protectionist compliant way of working, which undermines the quality of service and strategic objectives ostensibly being pursued by the changes. This paper warns against the pathology of public sector reforms pursuing enhanced service quality but achieving the opposite, and offers a possible way forward by engaging with public sector managers' identities, experiences and values.

This study's practical relevance derives from the profound comprehension of how public managers react to the "threats" to their role and everyday work. It offers a basis for reflecting upon the need to handle complexity. The findings shed light on the importance of highlighting the bright side of the complex challenges that are often seen as a dark cloud and threat to customs and continuity. This previously-unseen bright side can expose opportunities to turn complex organisational and relational dynamics into ameliorating opportunities for everyday activity. This paper offers a way to encourage public sector managers to stop being the recipients of others' decisions, and instead become active and powerful participants in changes that will support the public sector and its constituencies. Finally, the paper offers a practical contribution about the relevance of interdisciplinary training programs focusing on soft skills, communication and engagement as a way to support change in complex organisations. This goes far beyond the public sector into many other domains.

Before concluding, several caveats also need to be considered. First, the paper focuses on participants in a training program. This program produced reactions that offer interesting insights, but could also be prone to limitations related to the "abstract circumstances" in which they arose, and particularly the protected setting of a training program. Further research is needed to tap into these dynamics focusing on single organisations and examining how training and involvement could affect managers' performance. It would be interesting to investigate how identity work directly influences change processes within organisations, because the identity developed by participants through the training program could be challenged once they return to their organisations. This focus could also cover issues relating to the influence of contextual and cultural features in the process. These may be relevant because the heterogeneous backgrounds, workplaces and daily operational challenges of participants in our program may have limited our ability to identify these. There were relevant changes in the study setting, but the training course itself could be seen as a regime of truth and could have produced a framing effect among participants. Further developments of this project that are already in place are designed to provide an opportunity to explore how participants continued (or not) to evolve and why, which will hopefully overcome this limitation. Finally, this research has unveiled some important aspects that constitute an important and neglected area for investigation, related to emotional issues in change processes. This is even more important when we consider the view that identities are increasingly becoming networked and socially complex. They are now embedded in multiple social relations, emergent features of our inherent socialisation, and affected by varied social contexts. Further research could usefully consider social contexts and relations with a view to producing predictable differentials correlated to identities. Researchers may also investigate the extent to which social contexts, including but not limited to work contexts, can also be changed. This research could expand the accounting debate on the role of emotions (e.g., Repenning et al., 2021; 
Paracini et al., 2014; Carlsson et al., 2021), which promises to be an important area for the foreseeable future.

\section{End notes}

${ }^{1}$ DiSC is a behaviour assessment tool based on the DISC theory of psychologist William Moulton Marston. It centres on four different personality traits, Dominance (D), Influence (I), Steadiness (S), and Conscientiousness (C). This theory was developed into a behavioural assessment tool by industrial psychologist Walter Vernon Clarke.

\section{References}

Abernethy, MA and Vagnoni E. (2004). Power, organization design and managerial behaviour. Accounting, Organizations and Society, 29(3-4): 207-225.

Agyemang, G. and Broadbent, J. (2015), "Management control systems and research management in universities: An empirical and conceptual exploration", Accounting, Auditing \& Accountability Journal, 28(7): 1018-1046.

Allain E, Lemaire C, and Lux G (2021), Managers' subtle resistance to neoliberal reforms through and by means of management accounting, Accounting, Auditing \& Accountability Journal 34(3): 591-615.

Alvesson M and Spicer A (2012). A stupidity-based theory of organizations. Journal of Management Studies 49(7): 1194-1220.

Alvesson M and Willmott H (2002). Identity Regulation as Organizational Control: Producing the Appropriate Individual. Journal of Management Studies 39(5): 619-644.

Alvesson M, Lee Ashcraft K and Thomas R (2008). Identity matters: Reflections on the construction of identity scholarship in organization studies. Organization 15(1): 5-28.

Alvesson, M and Ashcraft KL (2012). 'Interviews'. In G. Symon and C. Cassell (eds), Qualitative Organizational Research: Core Methods and Current Challenges, pp. 239-257. London: Sage.

Bankins S and Waterhouse J (2019). Organizational identity, image, and reputation: Examining the influence on perceptions of employer attractiveness in public sector organizations. International Journal of Public Administration 42(3): 218-229.

Barratt E (2008). The later Foucault in organization and management studies. Human Relations 61(4): 515-537.

Baxter J (2002). Competing discourses in the classroom: A post-structuralist discourse analysis of girls' and boys' speech in public contexts. Discourse \& Society 13(6): 827-842.

Becker S, Jagalla S, Skærbæk P. (2014), The translation of accrual accounting and budgeting and the reconfiguration of public sector accountants' identities, Critical Perspectives on Accounting 25: $324-338$. 
Blomgren, M. (2003), 'Ordering a profession: Swedish nurses encounter new public management reforms', Financial Accountability \& Management, 19 (1): 45-71

Broadbent, J and Laughlin R (1998). 'Resisting the new public management'. Absorption and absorbing groups in schools and GP practices in the UK, Accounting, Auditing \& Accountability Journal, 11 (4): 403-435.

Broadbent, J and Laughlin R (2013). Accounting control and controlling accounting: Interdisciplinary and critical perspectives. Bingley: Emerald Group Publishing.

Broadbent, J, Jacobs K and Laughlin R (2001). 'Organisational resistance strategies to unwanted accounting and finance changes. The case of general medical practice in the UK.', Accounting, Auditing \& Accountability Journal, 14 (5): 565-586.

Brown AD (2006). A Narrative Approach to Collective Identities. Journal of Management Studies 43(4): 731-753.

Brown AD (2015). Identities and identity work in organizations. International Journal of Management Reviews 17(1): 20-40.

Brown AD (2017) Identity work and organizational identification. International Journal of Management Reviews, 19(3): 296-317.

Brown AD (2019). Identities in Organization Studies. Organization Studies 40(1): 7-22. 896.

Brown AD and Toyoki S (2013). Identity work and legitimacy. Organization Studies 34(7): 875-

Butler J (2005). Giving an account of oneself. Oxford: Oxford University Press.

Carlsson-Wall, M, Kraus, K, Lund, M. and SjögrenSjogren, E., (2016). 'Accounting talk' through metaphorical representations: change agents and organisational change in home-based elderly care. European Accounting Review, 25 (2): 215-243.

Carlsson-Wall, M., Kaarbøe, K., Kraus, K. and Meidell, A., 2021. Risk management as passionate imitation: the interconnections among emotions, performance metrics, and risk in a global technology firm. Abacus, 57(1), pp.72-100.]

Chartrand TL and Bargh JA (1999). The chameleon effect: the perception-behavior link and social interaction. Journal of Personality and Social Psychology 76(6): 893-910.

Chen Y and Reay T (2020). Responding to imposed job redesign: The evolving dynamics of work and identity in restructuring professional identity. Human Relations. Epub ahead of print 14 February 2020. DOI: $10.1177 / 0018726720906437$

Corlett S, McInnes P, Coupland C and Sheep M (2017). Exploring the registers of identity research. International Journal of Management Reviews 19(3): 261-272.

Costas J and Fleming P (2009). Beyond dis-identification: A discursive approach to selfalienation in contemporary organizations. Human Relations 62(3): 353-378. 
Du Gay P (1996). Consumption and identity at work. Thousand Oaks, CA: Sage.

Empson L. (2013). My Affair With the "Other": Identity Journeys Across the Research-Practice Divide. Journal of Management Inquiry, 22(2):229-248.

Fiondella, C., Macchioni, R., Maffei, M., \& Spanò, R. (2016). Successful changes in management accounting systems: A healthcare case study, Accounting Forum 40(3): 186-204.

Foucault M (1980). 'Truth and power'. In: Gordon C. (Ed.), Power/knowledge: Selected interviews and other writings 1972-1977 Michel Foucault. Brighton: Harvester, 109-133.

Foucault M (1981). The order of discourse. In: Young R (Ed.), Untying the text: A poststructuralist reader. London: Routledge and Kegan, 48-78.

Foucault M (1990). The will to knowledge: The history of sexuality. Volume 1. Middlesex: Penguin.

Foucault M. (1972/1989). The archaeology of knowledge (A.M. Sheridan Smith Trans.). London: Routledge.

Geier JG and Downey DE (1989). Energetics of personality: defining a self. Minneapolis: Aristos Publishing House/Geier Learning Systems.

Glynos J and Howarth D (2007). Logics of critical explanation in social and political theory. London: Routledge.

Goretzki L, Strauss E, and Weber J. (2013), An institutional perspective on the changes in MAs' professional role, Management Accounting Research, 24: 41-63.

Gurd, B and Thorne, H. (2003). The transformation of an accounting system during organisational change: a longitudinal study. Financial Accountability \& Management, 19: 21-43.

Hay GJ, Parker SK and Luksyte A. (2020). Making sense of organisational change failure: An identity lens. Human Relations. Epub ahead of print 27 February 2020. DOI: 10.1177/0018726720906211.

Hood C, James O and Scott C (2000). Regulation of government: has it increased, is it increasing, should it be diminished?. Public Administration, 78(2): 283-304.

Hoque, Z., S. Arends and R. Alexander (2004), 'Policing the police service. A case study of the rise of "new public management" within an Australian police service', Accounting, Auditing \& Accountability Journal, 17 (1): 59-84

Huber G and Brown AD (2017). Identity Work, Humour and Disciplinary Power. Organization Studies 38(8): 1107-1126.

Jacobs, K (2005), 'Hybridization or polarization: doctors and accounting in the UK, Germany and Italy', Financial Accountability \& Management, 21 (2): 135-161.

Jacobs, K., Marcon, G., \& Witt, D. (2004). Cost and performance information for doctors: an international comparison. Management Accounting Research, 15(3), 337-354. 
Järvinen, J (2006), 'Institutional pressures for adopting new cost accounting systems in Finish hospitals: two longitudinal case studies', Financial Accountability \& Management, 22 (1): 21-46.

Järvinen, J (2009). 'Shifting NPM agendas and management accountants' occupational identities', Accounting, Auditing \& Accountability Journal, 22(8): 1187-1210.

Jönsson, S. and Solli, R., 1993. 'Accounting talk' in a caring setting. Management Accounting Research, 4(4), pp.301-320

Kärreman D and Alvesson M (2004). Cages in tandem: Management control, social identity, and identification in a knowledge-intensive firm. Organization 11(1): 149-175.

Kärreman D and Alvesson M (2009). Resisting resistance: Counter-resistance, consent and compliance in a consultancy firm. Human Relations 62(8): 1115-1144.

Knights D (2002). Writing organizational analysis into Foucault. Organization 9(4): 575-593.

Kurunmäki, L (2004), 'A hybrid profession - the acquisition of management accounting expertise by medical professionals', Accounting, Organizations and Society, 29 (3-4): 327-347.

Kurunmäki, L and Miller P (2006), 'Modernising government: The calculating self, hybridisation and performance measurement', Financial Accountability \& Management, 22(1): 87-106.

Kurunmäki, L, Lapsley I and Melia K (2003), 'Accountingization v. legitimation: a comparative study of the use of accounting information in intensive care', Management Accounting Research, 14 (2): 112-139.

Laclau E and Mouffe C (1985) Hegemony and socialist strategy: Towards a radical democratic politics. London: Verso Trade.

Laughlin R (1991). Can the information systems for the NHS internal market work?. Public money \& management, 11(3): 37-41.

Liguori M and Steccolini I (2014). Accounting, innovation and public-sector change. Translating reforms into change? Critical Perspectives on Accounting 25(4-5): 319-323.

Meyer RE and Hammerschmid G (2006). Changing institutional logics and executive identities: A managerial challenge to public administration in Austria. American Behavioral Scientist 49(7): 1000-1014.

Meyer RE, Egger-Peitler I, Höllerer MA and Hammerschmid G (2014). Of Bureaucrats and Passionate Public Managers: Institutional Logics, Executive Identities, And Public Service Motivation. Public Administration 92(4): 861-885.

Mir, MZ, and Rahaman, AS (2006). Leadership, accounting, and the reform process of a public sector agency: A narrative analysis. Financial Accountability \& Management, 22(2), 157-178.

Motley D and Hartley N (2005). The changing role of personality instruments in assessing behaviour in the classroom. Teaching Economics: Instruction and Classroom-Based Research. Pittsburgh: Society for the Advancement of Management. 
Munro I (2014). Organizational ethics and Foucault's 'art of living': Lessons from social movement organizations. Organization Studies, 35(8): 1127-1148.

Palma PJ, Pina E Cunha M, and Lopes MP (2010). The best of two worlds: How privatization affects the identity of a public organization. Public Management Review 12(5): 725-746.

Paracini, H., Malsch, B. and Paillé, A.M., 2014. Fear and risk in the audit process. Accounting, Organizations and Society, 39(4), pp.264-288.

Parker LD (2009). Photo-elicitation: an ethno-historical accounting and management research prospect. Accounting Auditing \& Accountability Journal 22(7): 1111-1129.

Parker LD and Jeacle I (2019). The Construction of the Efficient Office: Scientific Management, Accountability and the Neo-Liberal State. Contemporary Accounting Research 36(3): 1883-1926.

Parker LD and Warren S (2017). The presentation of the self and professional identity: countering the accountant's stereotype. Accounting, Auditing \& Accountability Journal 30(8) 1895-1924.

Petriglieri, G., and Stein, M. (2012). The unwanted self: Projective identification in leaders' identity work. Organization Studies, 33(9), 1217-1235.

Qu, S.Q. and Dumay, J. (2011), The qualitative research interview. Qualitative Research in Accounting \& Management, 8 (3): 238-264.

Rautiainen, A, and Järvenpää, M (2012). Institutional logics and responses to performance measurement systems. Financial Accountability \& Management, 28(2): 164-188.

Ravasi, D. (2017). Visualizing our way through theory building. Journal of Management Inquiry, 26(2), 240-243.

Repenning, N., Löhlein, L., \& Schäffer, U. (2021). Emotions in Accounting: A Review to Bridge the Paradigmatic Divide. European Accounting Review, 1-27.

Robbins, G. (2007). Obstacles to implementation of new public management in an Irish hospital. Financial Accountability \& Management, 23(1): 55-71.

Rodrigues S and Child J (2008). The Development of Corporate Identity: A Political Perspective. Journal of Management Studies 45(5): 885-911.

Runfola, A, Perna, A, Baraldi, E, and Gregori, GL (2017). The use of qualitative case studies in top business and management journals: A quantitative analysis of recent patterns. European Management Journal 35(1), 116-127.

Saunders, MN, and Townsend, K. (2016). Reporting and justifying the number of interview participants in organization and workplace research. British Journal of Management, 27(4), 836-852.

Skålén P (2004). New public management reform and the construction of organizational identities. International Journal of Public Sector Management 17(3): 251-263. 
Skjælaaen, GR, Bygdås, AL, and Hagen, AL (2020). Visual inquiry: exploring embodied organizational practices by collaborative film-elicitation. Journal of Management Inquiry, 29(1), 5975 .

Slay HS and Smith DA (2011). Professional identity construction: Using narrative to understand the negotiation of professional and stigmatized cultural identities. Human Relations 64(1): 85-107.

Spanò R (2018). L'accounting change nel settore pubblico: fondamenti, determinanti e proposte di rilettura. Torino: Giappichelli.

Spanò R, Caldarelli A, Ferri L and Maffei M. (2020). Context, culture and control: a case study on accounting change in an Italian regional health service. Journal of Management and Governance, 24(1): 229-272.

Sveningsson S and Alvesson M (2003). Managing managerial identities: Organizational fragmentation, discourse and identity struggle. Human Relations 56(10): 1163-1193.

Thomas R and Davies A (2005). Theorizing the micro-politics of resistance: New public management and managerial identities in the UK public services. Organization Studies 26(5): 683706.

Thornborrow, T, and Brown, AD (2009). Being regimented': Aspiration, discipline and identity work in the British parachute regiment. Organization studies, 30(4), 355-376.

Tomo A (2018), Managerialism in the public sector. Perspectives and prospects, London: Routledge.

Tomo A and Spanò R (2020), Strategising identity in the accounting profession: 'mirror, mirror on the wall, who is the accountant of them all?' Meditari Accountancy Research, Epub ahead of print 18 April 2020. DOI: 10.1108/MEDAR-02-2019-0443.

van Bockel J and Noordegraaf M (2006). Identifying identities: performance-driven, but professional public managers. International Journal of Public Sector Management, 19(6): 585-597.

Warren S (2005). Photography and voice in critical qualitative management research, Accounting, Auditing \& Accountability Journal 18(6): 861-882.

Warren S and Parker LD (2009). Bean counters or bright young things? Towards the visual study of identity construction among professional accountants. Qualitative Research in Accounting \& Management 6(4): 205-223.

Watson TJ (2008). Managing identity: Identity work, personal predicaments and structural circumstances. Organization 15(1): 121-143.

Watson TJ (2009), "Narrative, life story and manager identity: A case study in autobiographical identity work", Human Relations, 62(3): 425-452.

Weedon C (1997). Feminist practice and poststructuralist theory, Wiley-Blackwell 
Wright C, Nyberg D and Grant D (2012). 'Hippies on the third floor': Climate change, narrative identity and the micro-politics of corporate environmentalism. Organization Studies 33(11): 14511475.

Zanoni P, Thoelen A and Ybema S (2017). Unveiling the subject behind diversity: Exploring the micro-politics of representation in ethnic minority creatives' identity work. Organization 24(3): 330354.

\section{Appendix}

1. We explained the subject and aim of the research and clarified that the "activity" promoted was an integral part of the MPA, and that there were neither expected "right answers" nor predetermined expectations of performance.

2. We agreed a convenient time to organize the interviews and asked for permission to record conversations.

3. We asked participants to bring to our meeting a picture that they believed to be a good representation of how they feel in relation to their work role in the highly dynamic environment of the Italian public sector. We told them that these pictures would be the starting point for the interviews and to make sure that each photo should say "This is me!" representing or symbolising the participant's professional identity.

4. We also warned participants to reflect upon the images produced in terms of "This is me! But I do not want this to be me!" to unveil any possible emotional conflict.

We asked the participants:

a) to describe their own pictures and to explain what the pictures symbolised in terms of their professional daily practice;

b) to describe their professional practice, the challenges, the obstacles, the success that they experience every day, their attitude and reactions with reference to these circumstances, and with them tried to relate the images produced to all the situations described;

c) to comment the positive and negative feelings emerging from the representation, and to tell us whether these emotions remain at their workplace or exert any influence in their daily life, also recalling examples;

d) to provide a very general opinion about their assessment of the opportunity for and likelihood of change.

Table 1. Participants interviewed

\begin{tabular}{|c|c|c|c|c|c|c|}
\hline ID & Age & Degree & Public Administration & $\begin{array}{c}\text { Type of } \\
\text { employment }\end{array}$ & $\begin{array}{c}\text { Total length } \\
\text { of the two } \\
\text { interviews }\end{array}$ \\
\hline$\# 1$ & 38 & Economics & Ministry of Justice & middle level & Accounting \& Finance & 80 minutes \\
\hline$\# 2$ & 47 & Economics & University & middle level & Human Resources Management & 75 minutes \\
\hline$\# 3$ & 47 & Economics & $\begin{array}{c}\text { Ministry of Economics } \\
\text { and Finance }\end{array}$ & top level & Accounting \& Finance & 90 minutes \\
\hline
\end{tabular}




\begin{tabular}{|c|c|c|c|c|c|c|}
\hline \#4 & 55 & $\begin{array}{l}\text { Veterinary } \\
\text { medicine }\end{array}$ & $\begin{array}{c}\text { Ministry of Health - } \\
\text { Customs of Salerno } \\
\text { Harbour }\end{array}$ & top level & Management \& Control & 85 minutes \\
\hline \#5 & 46 & Law & Local Administration & middle level & Human Resources Management & 70 minutes \\
\hline \#6 & 51 & Law & $\begin{array}{c}\text { Institute for Social } \\
\text { Welfare }\end{array}$ & top level & Accounting \& Finance & 90 minutes \\
\hline \#7 & 49 & Law & University & middle level & Management \& Control & 90 minutes \\
\hline \#8 & 50 & Economics & $\begin{array}{c}\text { Italian National Research } \\
\text { Council }\end{array}$ & top level & Management \& Control & 75 minutes \\
\hline$\# 9$ & 39 & Law & Ministry of Justice & middle level & Accounting \& Finance & 80 minutes \\
\hline$\# 10$ & 56 & Law & Ministry of Labour & middle level & Compliance manager & 85 minutes \\
\hline$\# 11$ & 46 & $\begin{array}{l}\text { Veterinary } \\
\text { medicine }\end{array}$ & Zooprophylactic institute & top level & General Management & 95 minutes \\
\hline$\# 12$ & 34 & Mathematics & Ministry of Education & middle level & IT manager & 90 minutes \\
\hline$\# 13$ & 42 & Economics & Ministry of Justice & middle level & Accounting \& Finance & 70 minutes \\
\hline$\# 14$ & 44 & Political Sciences & Local Administration & middle level & Accounting \& Finance & 80 minutes \\
\hline$\# 15$ & 43 & Law & Ministry of Labour & middle level & Compliance Manager & 95 minutes \\
\hline$\# 16$ & 48 & Architecture & $\begin{array}{c}\text { Ministry of } \\
\text { Transportation }\end{array}$ & middle level & Operation Manager & 85 minutes \\
\hline$\# 17$ & 52 & Political Sciences & University & middle level & Human Resources Management & 80 minutes \\
\hline$\# 18$ & 35 & Architecture & Local Administration & middle level & Operation Manager & 90 minutes \\
\hline$\# 19$ & 35 & Law & $\begin{array}{c}\text { Institute for Social } \\
\text { Welfare } \\
\end{array}$ & top level & Management \& Control & 95 minutes \\
\hline \#20 & 53 & Law & $\begin{array}{l}\text { Ministry of Economics } \\
\text { and Finance }\end{array}$ & top level & Accounting \& Finance & 90 minutes \\
\hline$\# 21$ & 46 & $\begin{array}{l}\text { Veterinary } \\
\text { medicine }\end{array}$ & Zooprophylactic institute & top level & Management \& Control & 85 minutes \\
\hline$\# 22$ & 33 & Economics & Local Administration & middle level & Accounting \& Finance & 95 minutes \\
\hline$\# 23$ & 48 & Law & University & middle level & Accounting \& Finance & 90 minutes \\
\hline$\# 24$ & 55 & Law & Ministry of Justice & top level & General Management & 90 minutes \\
\hline$\# 25$ & 41 & Law & Local Administration & middle level & Management \& Control & 80 minutes \\
\hline$\# 26$ & 51 & Law & Local Health Institute & top level & Human Resources Management & 75 minutes \\
\hline$\# 27$ & 43 & Political Sciences & $\begin{array}{c}\text { Institute for Social } \\
\text { Welfare } \\
\end{array}$ & middle level & Accounting \& Finance & 90 minutes \\
\hline$\# 28$ & 41 & Sociology & $\begin{array}{l}\text { Local-Regional } \\
\text { Administration } \\
\end{array}$ & middle level & Human Resources Management & 85 minutes \\
\hline$\# 29$ & 35 & Economics & Italian Revenue Service & middle level & Accounting \& Finance & 95 minutes \\
\hline
\end{tabular}


Table 2. Grouping of participants before the training

\begin{tabular}{|c|c|c|}
\hline DiSC test category & No. of participants & $\begin{array}{l}\text { DiSC characteristics } \\
\text { matched with image messages }\end{array}$ \\
\hline Affable (S) & 3 & rigidity and confusion \\
\hline Analyst (S, C) & 9 & $\begin{array}{l}\text { rigidity, loneliness, ceremonial } \\
\text { perception }\end{array}$ \\
\hline Individualist (C) & 4 & contrasting emotions and uncertainty \\
\hline Involver (I, C) & 2 & emotions and internalisation \\
\hline Persuader (D) & 5 & superiority and easiness \\
\hline Promoter (I) & 2 & proactivity and purposefuless \\
\hline Systematic (C) & 2 & huge confusion \\
\hline Supporter (S) & 2 & uncertainty, doubts, loneliness \\
\hline
\end{tabular}


Table 3. Grouping of participants after the training

\begin{tabular}{|c|c|c|c|}
\hline $\begin{array}{l}\text { DiSC test } \\
\text { category }\end{array}$ & No. of participants & $\begin{array}{l}\text { Previous DiSC test } \\
\text { category }\end{array}$ & $\begin{array}{l}\text { DiSC characteristics } \\
\text { matched with image messages }\end{array}$ \\
\hline Affable (S) & 2 & $\begin{array}{l}1 \text { persuader and } 1 \\
\text { analyst }\end{array}$ & $\begin{array}{l}\text { rigidity and mess, but awareness and } \\
\text { consciousness }\end{array}$ \\
\hline Analyst (S, C) & 2 & 1 analyst and 1 affable & $\begin{array}{l}\text { rigidity, loneliness, but perceived change of } \\
\text { perspective }\end{array}$ \\
\hline Deducer (I) & 3 & $\begin{array}{l}2 \text { analyst and } 1 \\
\text { promoter }\end{array}$ & $\begin{array}{c}\text { awareness, self-confidence, recognition of one's } \\
\text { role, serenity }\end{array}$ \\
\hline Director (D) & 2 & $\begin{array}{l}1 \text { supporter and } 1 \\
\text { persuader }\end{array}$ & $\begin{array}{l}\text { self-confidence, recognition of one's role, } \\
\text { proactive approach, but frustration }\end{array}$ \\
\hline Empathiser (I) & 2 & $\begin{array}{l}1 \text { systematic and } 1 \\
\text { analyst }\end{array}$ & serenity, self-confidence, change of perspective \\
\hline Evaluator $(\mathrm{C})$ & 4 & $\begin{array}{c}1 \text { systematic, } 1 \\
\text { individualist, } 1 \text { analyst, } \\
1 \text { supporter }\end{array}$ & $\begin{array}{l}\text { consciousness contrasting with frustration and } \\
\text { uncertainty }\end{array}$ \\
\hline Individualist $(\mathrm{C})$ & 2 & individualist & contrasting emotions and uncertainty \\
\hline Involver (I, C) & 3 & 1 involver and 2 analyst & $\begin{array}{c}\text { Positivity ad profound emotions, notwithstanding } \\
\text { disorientation }\end{array}$ \\
\hline Persuader (D) & 2 & 2 persuader & superiority \\
\hline Producer $(\mathrm{S})$ & 1 & affable & contrasting emotions, openness with prudence \\
\hline Specialist (S) & 2 & $\begin{array}{l}1 \text { analyst and } 1 \\
\text { promoter }\end{array}$ & curiosity, openness, but fear of disorganization \\
\hline Systematic (C) & 3 & $\begin{array}{l}1 \text { affable, } 1 \text { analyst, } 1 \\
\text { persuader }\end{array}$ & less rigidity and greater self-awareness \\
\hline Supporter (S) & 1 & individualist & instability but courage to go on \\
\hline
\end{tabular}


Figure 1. Woman at the window

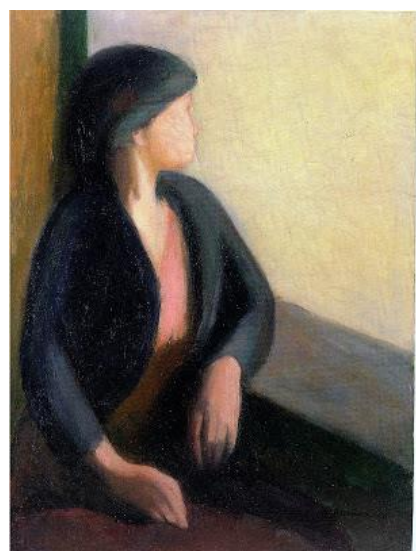

Ragazza alla finestra (G. Roma) - Pinacoteca Alberto Martini Oderzo.

Figure 2. Torn

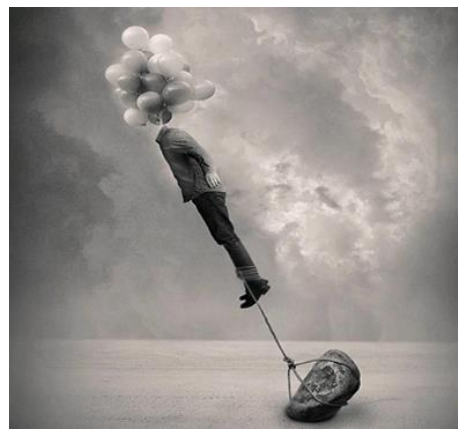

Credits: T. Ingberg

Figure 3. Italian Garden

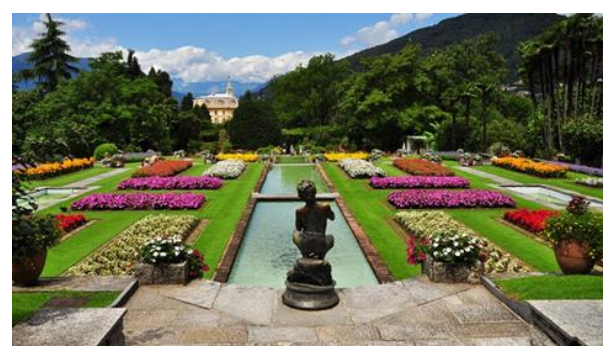

Figure 4. Crash

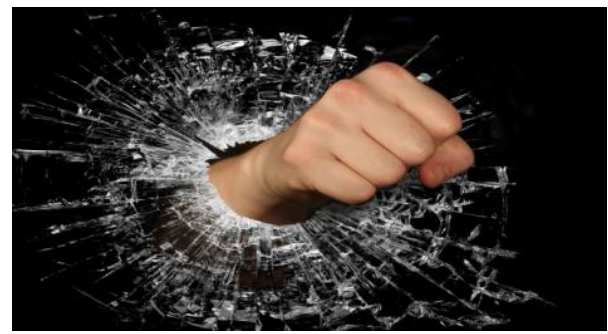


Figure 5. Crowd

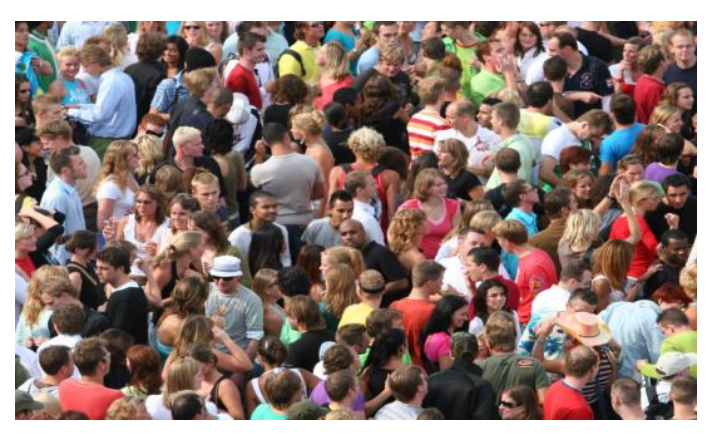

Figure 6. English Garden

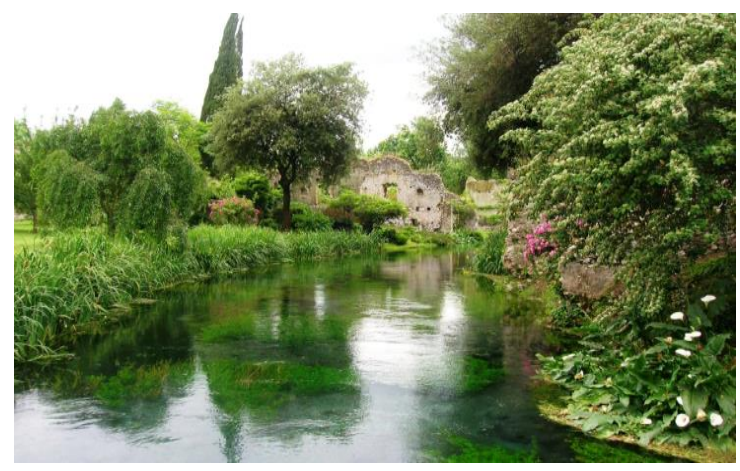

Figure 7. Blind woman

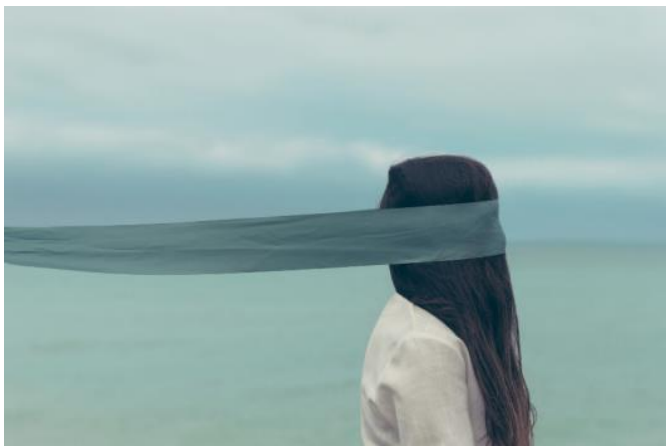

